Article

\title{
A New 2-(2-Phenylethyl)Chromone from Chinese Eaglewood
}

\author{
Hao-Fu Dai, Jun Liu, Yan-Bo Zeng, Zhuang Han, Hui Wang and Wen-Li Mei *
}

Key Laboratory of Tropical Crop Biotechnology, Ministry of Agriculture, Institute of Tropical

Bioscience and Biotechnology, Chinese Academy of Tropical Agricultural Sciences, Haikou 571101, China; E-Mails: hfdai2001@yahoo.com.cn (H-F.D.); jollyliu1983@163.com (J.L.); zengyanbo@163.com (Y-B.Z.); hanzone@yahoo.cn (Z.H.); wanghuilily2000@163.com (H.W.)

* Author to whom correspondence should be addressed; E-Mail: meiwenli@yahoo.com.cn.

Received: 17 November 2009; in revised form: 8 December 2009 / Accepted: 8 December 2009 / Published: 9 December 2009

\begin{abstract}
A new 2-(2-phenylethyl)chromone, 5,6,7,8-tetrahydroxy-2-(3-hydroxy-4methoxyphenethyl)-5,6,7,8-tetrahydro-4H-chromen-4-one (1) was isolated from the Chinese eaglewood [Aquilaria sinensis (Lour.) Gilg]. Its structure was established by detailed MS and NMR spectroscopic analysis, as well as comparison with literature data.
\end{abstract}

Keywords: Chinese eaglewood; Aquilaria sinensis; chromone

\section{Introduction}

Chinese eaglewood is the resin-deposited part of the trunk of Aquilaria sinensis (Lour.) Gilg, which has been used in China as incense as well as a traditional sedative, analgesic and digestive medicine [1]. Characteristic sesquiterpenes and chromone derivatives have been isolated from Chinese eaglewood in recent decades [2-4]. In our previous screening for cytotoxic agents from tropical medicinal plants, a new cytotoxic 2-(2-phenylethyl)chromone has been isolated from Chinese eaglewood collected in Hainan Province of China [5]. Continued study on the chemical constituents from Chinese eaglewood led to the isolation of a new 2-(2-phenylethyl)chromone, 5,6,7,8-tetrahydroxy-2-(3-hydroxy-4-methoxyphenethyl)-5,6,7,8-tetrahydro-4H-chromen-4-one (1). The present paper describes the isolation and structural elucidation of the new compound. 


\section{Results and Discussion}

Compound 1 was isolated as pale yellow powder, mp $109-111^{\circ} \mathrm{C},[\alpha]_{18}^{\mathrm{D}}+12.3($ c $1.0, \mathrm{MeOH})$. The $[\mathrm{M}+\mathrm{Na}]^{+}$at $\mathrm{m} / \mathrm{z} 387.1053$ (calcd. 387.1056) in the high-resolution ESI-Mass spectrum corresponded to the molecular formula $\mathrm{C}_{18} \mathrm{H}_{20} \mathrm{O}_{8}$. This formula can also be validated through ${ }^{1} \mathrm{H}-\mathrm{NMR},{ }^{13} \mathrm{C}-\mathrm{NMR}$ and DEPT spectra. Its IR spectrum showed the presence of hydroxyl $\left(3,409 \mathrm{~cm}^{-1}\right)$, unsaturated carbonyl $\left(1,652 \mathrm{~cm}^{-1}\right)$ and phenyl $\left(1,570,1,514,1,456 \mathrm{~cm}^{-1}\right)$ groups. The ${ }^{1} \mathrm{H}-\mathrm{NMR}$ spectrum (Table 1) of $\mathbf{1}$ showed the presence of one methoxyl group at $\delta_{\mathrm{H}} 3.71(3 \mathrm{H}, \mathrm{s})$, four consecutive methine protons $\left[\delta_{\mathrm{H}}\right.$ $4.48(1 \mathrm{H}, \mathrm{d}, J=4.2 \mathrm{~Hz}, \mathrm{H}-5), 3.74(1 \mathrm{H}, \mathrm{dd}, J=6.9,4.2 \mathrm{~Hz}, \mathrm{H}-6), 3.83$ (1H, t, $J=6.9, \mathrm{H}-7)$, and 4.31 $(1 \mathrm{H}, \mathrm{d}, J=6.9 \mathrm{~Hz}, \mathrm{H}-8)]$, two methylene groups at $\delta_{\mathrm{H}} 2.80(4 \mathrm{H}$, overlapped, H-7', 8') and one 1,3,4trisubstituted phenyl group at $\delta_{\mathrm{H}} 6.80\left(1 \mathrm{H}, \mathrm{d}, J=8.0 \mathrm{~Hz}, \mathrm{H}-5^{\prime}\right), \delta_{\mathrm{H}} 6.67\left(1 \mathrm{H}, \mathrm{d}, J=1.9 \mathrm{~Hz}, \mathrm{H}-2^{\prime}\right)$ and $\delta_{\mathrm{H}} 6.60\left(1 \mathrm{H}, \mathrm{dd}, J=8.0,1.9 \mathrm{~Hz}, \mathrm{H}-6^{\prime}\right)$. The ${ }^{13} \mathrm{C}-\mathrm{NMR}$ spectrum (Table 1) of 1 showed the presence of two methylene groups at $\delta_{\mathrm{C}} 31.1$ and 34.3 , one methoxyl at $\delta_{\mathrm{C}} 55.6$ and four consecutive methine carbons $\left(\delta_{\mathrm{C}} 64.7, \delta_{\mathrm{C}} 72.7, \delta_{\mathrm{C}} 70.6\right.$ and $\left.\delta_{\mathrm{C}} 68.4\right)$. Based on the above evidence, compound 1 was presumed to be 2-(2-phenylethyl)chromone derivative. The ${ }^{13} \mathrm{C}$-NMR spectra of $\mathbf{1}$ was similar to that of the 8-chloro-5,6,7-trihydroxy-2-(3-hydroxy-4-methoxyphenethyl)-5,6,7,8-tetrahydro-4H-chromen4-one [5] except that C-8 was substituted by a hydroxyl group instead of a chlorine atom. The relative stereochemistry was determined by ${ }^{1} \mathrm{H}-{ }^{1} \mathrm{H}$ coupling constants. The relatively small coupling constant between H-5 and H-6 revealed the cis relationship between H-5 and H-6 [6]. While the relatively large coupling constants between H-6 and H-7, H-7 and H-8, revealed the trans relationships between them [7]. The relative stereochemistry of compound 1 was also confirmed by the ROESY experiment. In the ROESY spectrum, the cross peaks from $\delta 4.31(\mathrm{H}-8)$ to $\delta 4.48(\mathrm{H}-5)$ and $3.74(\mathrm{H}-6)$ indicated that $\mathrm{H}-5$, H-6 and H-8 were at the same side. While the cross peak from $\delta 4.48(\mathrm{H}-5)$ to $\delta 3.83(\mathrm{H}-7)$ was not observed, which indicated H-5 and H-7 were at the different side. Consequently, the structure of 1 was established as 5,6,7,8-tetrahydroxy-2-(3-hydroxy-4-methoxyphenethyl)-5,6,7,8-tetrahydro-4H-chromen-4-one. The result of bioactive assay showed that compound $\mathbf{1}$ exhibited no cytotoxic activity against K562, SGC-7901, SMMC-7721 cell lines.

Figure 1. Structure and key correlations of compound 1.
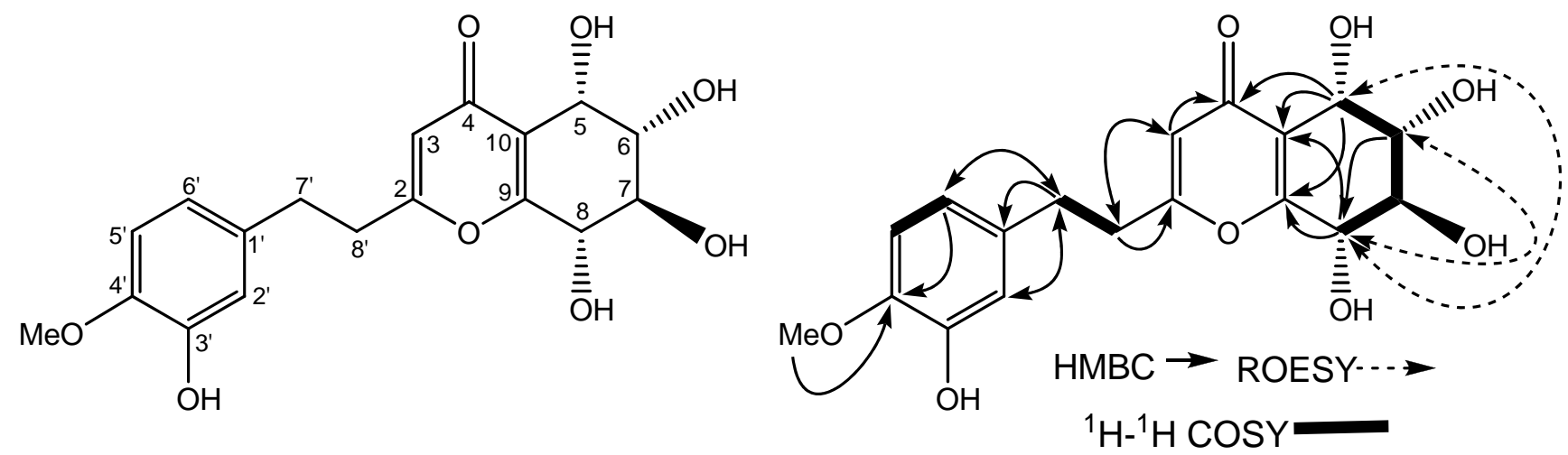
Table 1. NMR data of 1 in DMSO- $d_{6}\left({ }^{1} \mathrm{H}: 400 \mathrm{MHz} ;{ }^{13} \mathrm{C}: 100 \mathrm{MHz} ; \delta\right.$ in ppm, $J$ in $\left.\mathrm{Hz}\right)$.

\begin{tabular}{cllcll}
\hline Position & $\delta_{\mathrm{H}}$ & $\delta_{\mathrm{C}}$ & Position & $\delta_{\mathrm{H}}$ & $\delta_{\mathrm{C}}$ \\
\hline 2 & & 168.0 & $1^{\prime}$ & & 132.6 \\
3 & $6.07(1 \mathrm{H}, \mathrm{s})$ & 112.7 & $2^{\prime}$ & $6.67(1 \mathrm{H}, \mathrm{d}, 1.9)$ & 115.6 \\
4 & & 178.5 & $3^{\prime}$ & & 146.0 \\
5 & $4.48(1 \mathrm{H}, \mathrm{d}, 4.2)$ & 64.7 & $4^{\prime}$ & & 146.3 \\
6 & $3.74(1 \mathrm{H}, \mathrm{dd}, 6.9,4.2)$ & 72.7 & $5^{\prime}$ & $6.80(1 \mathrm{H}, \mathrm{d}, 8.0)$ & 112.2 \\
7 & $3.83(1 \mathrm{H}, \mathrm{t}, 6.9)$ & 70.6 & $6^{\prime}$ & $6.60(1 \mathrm{H}, \mathrm{dd}, 8.0,1.9)$ & 118.7 \\
8 & $4.31(1 \mathrm{H}, \mathrm{d}, 6.9)$ & 68.4 & $7^{\prime}$ & $2.80(2 \mathrm{H}$, overlapped $)$ & 31.1 \\
9 & & 163.1 & $8^{\prime}$ & $2.80(2 \mathrm{H}$, overlapped $)$ & 34.3 \\
10 & & 120.7 & $4^{\prime}-\mathrm{OCH}_{3}$ & $3.71(3 \mathrm{H}, \mathrm{s})$ & 55.6 \\
\hline
\end{tabular}

\section{Experimental}

\subsection{General}

Melting points were obtained on a Beijing Taike X-5 stage apparatus and are uncorrected. Optical rotation was recorded using a Rudolph Autopol III polarimeter (Rodolph Research Analytical, New Jersey, USA). The IR spectra were obtained on a Nicolet 380 FT-IR instrument, as KBr pellets. The NMR spectra were recorded on a Bruker AV-400 spectrometer, using TMS as an internal standard. The HRESIMS spectra were measured with an API QSTAR Pulsar mass spectrometer. Column chromatography was performed with silica gel (Marine Chemical Industry Factory, Qingdao, P. R. China), Sephadex LH-20 and Rp-18 gel (Merck, Darmstadt Germany). TLC was preformed with silica gel GF254 (Marine Chemical Industry Factory, Qingdao, P. R. China).

\subsection{Plant Material}

The material of Chinese eaglewood was collected in Ding'an county of Hainan Province, China, in May 2006, and the material was identified by Professor Hao-Fu Dai. A voucher specimen (No. CX20060501) is deposited in the Institute of Tropical Bioscience and Biotechnology, Chinese Academy of Tropical Agricultural Sciences.

\subsection{Extraction and Isolation}

The material of Chinese eaglewood $(35.4 \mathrm{Kg})$ was exhaustively extracted with $95 \% \mathrm{EtOH}$ three times at room temperature and filtered. After evaporation, the residue was suspended in $\mathrm{H}_{2} \mathrm{O}$ and partitioned with EtOAc to afford EtOAc extract. The $\mathrm{H}_{2} \mathrm{O}$ part was applied to a D101 reticular resin column eluted with $\mathrm{H}_{2} \mathrm{O}$ and $\mathrm{MeOH}$. The $\mathrm{MeOH}$ eluent was concentrated in vacuo to give a residue (147.3 g), which was chromatographed on a silica gel column (200-300 mesh) with gradient elution utilizing $\mathrm{CHCl}_{3}-\mathrm{MeOH}$ as solvent system to give nine fractions. Fraction 7 (25.8 g) was chromatographed on a RP-18 column with gradient elution of $\mathrm{MeOH}-\mathrm{H}_{2} \mathrm{O}$ as solvent system to give 10 fractions (Fr.7-1 10). Fraction 7-7 (4.1 g) was subjected to column chromatography over Sephadex LH-20 eluted with $95 \%$ EtOH and further purified by silica gel column chromatography eluted with $\mathrm{CHCl}_{3}-\mathrm{MeOH}$ (9:1) to afford 5,6,7,8-tetrahydroxy-2-(3-hydroxy-4-methoxyphenethyl)-5,6,7,8-tetra- 
hydro-4H-chromen-4-one (1, $119 \mathrm{mg})$. Pale yellow powder, $\mathrm{C}_{18} \mathrm{H}_{20} \mathrm{O}_{8}, \mathrm{mp} 109-111{ }^{\circ} \mathrm{C},[\alpha]{ }_{18}^{\mathrm{D}}+12.3$ (c $1.0, \mathrm{MeOH})$. IR (KBr) $v_{\max }\left(\mathrm{cm}^{-1}\right): 3,409,1,652,1,570,1,514,1,456,1,285,1,110,1,049 .{ }^{1} \mathrm{H}-$ and ${ }^{13} \mathrm{C}-\mathrm{NMR}$ spectral data: see Table 1; HREI-ESI-MS m/z: $387.1053[\mathrm{M}+\mathrm{Na}]^{+}$(calcd. for $\mathrm{C}_{18} \mathrm{H}_{20} \mathrm{O}_{8} \mathrm{Na}$, 387.1056).

\section{Conclusions}

As a part of our chemical investigation on Chinese eaglewood [Aquilaria sinensis (Lour.) Gilg], a new 2-(2-phenylethyl)chromone, 5,6,7,8-tetra-hydroxy-2-(3-hydroxy-4-methoxyphenethyl)-5,6,7,8tetrahydro-4H-chromen-4-one (1) was isolated. Its structure was established on the basis of spectroscopic evidence. The result of bioactive assay showed that compound $\mathbf{1}$ exhibited no cytotoxic activity against K562, SGC-7901, SMMC-7721 cell lines.

\section{Acknowledgements}

This research was financially supported by National Nonprofit Institute Research Grant of CATASITBB (No. ITBBZD2007-4-3) and the Science and Technology Foundation of Chinese Academy of Tropical Agricultural Sciences (No. RKY0726).

\section{References and Notes}

1. Institute of Materia Medica of Chinese Academy of Medical Sciences. Modern Research on Chinese Herbal Medicine, 3; Peking Medical College and Peking Union Medical College Associated Press: Beijing, China, 1997; p. 1.

2. Dai, H.F.; Mei, W.L. Modern Research on Medicinal Plants in Hainan; China Science and Technology Press: Beijing, China, 2007; p. 31.

3. Mei, W.L.; Zeng, Y.B.; Liu, J.; Dai, H.F. GC-MS analysis of volatile constituents from five different kinds of Chinese eaglewood. J. Chin. Med. Mat. 2007, 30, 551-555.

4. Mei, W.L.; Zeng, Y.B.; Wu, J.; Cui, H.B.; Dai, H.F. Chemical composition and anti-MRSA activity of the essential oil from Chinese eaglewood. J. Chin. Pharm. Sci. 2008, 17, 225-229.

5. Liu, J.; Wu, J.; Zhao, Y.X.; Deng, Y.Y.; Mei, W.L.; Dai, H.F. A new cytotoxic 2-(2phenylethyl)chromone from Chinese eaglewood. Chin. Chem. Lett. 2008, 19, 934-936.

6. Yagura, T.; Shibayama, N.; Ito, M.; Kiuchi, F.; Honda, G. Three novel diepoxy tetrahydrochromones from agarwood artificially produced by intentional wounding. Tetrahedron Lett. 2005, 46, 4395-4398.

7. Yagura, T.; Ito, M.; Kiuchi, F.; Honda, G.; Shimada, Y. Four new 2-(2-phenylethyl)chromone derivatives from withered wood of Aquilaria sinensis. Chem. Pharm. Bull. 2003, 51, 560-564.

Sample Availability: Samples of compound $\mathbf{1}$ are available from the authors.

(C) 2009 by the authors; licensee Molecular Diversity Preservation International, Basel, Switzerland. This article is an open-access article distributed under the terms and conditions of the Creative Commons Attribution license (http://creativecommons.org/licenses/by/3.0/). 